\title{
Selecting Double Bond Positions with a Single Cation- Responsive Iridium Olefin Isomerization Catalyst
}

\author{
Andrew M. Camp, Matthew R. Kita, P. Thomas Blackburn, Henry M. Dodge, Chun-Hsing Chen, and
} Alexander J. M. Miller ${ }^{*}$

\author{
Department of Chemistry, University of North Carolina at Chapel Hill, Chapel Hill, North Carolina 27599-3290, United \\ States
}

\begin{abstract}
The catalytic transposition of double bonds holds promise as an ideal route to alkenes with value as fragrances, commodity chemicals, and pharmaceuticals; yet, selective access to specific isomers is a challenge, requiring independent development of different catalysts for different products. In this work, a single cation-responsive iridium catalyst is developed for the selective production of either of two different internal alkene isomers. In the absence of salts, a single positional isomerization of 1-butene derivatives furnishes 2-alkenes with exceptional regioselectivity and stereoselectivity. The same catalyst, in the presence of $\mathrm{Na}^{+}$, mediates two positional isomerizations to produce 3-alkenes. The synthesis of new iridium pincer-crown ether catalysts based on an aza-18-crown-6 ether proved instrumental in achieving cation-controlled selectivity. Experimental and computational studies guided the development of a mechanistic model that explains the observed selectivity for various functionalized 1-butenes, providing insight into strategies for catalyst development based on non-covalent modifications.
\end{abstract}

\section{INTRODUCTION}

Olefins are essential intermediates and products in the fragrance, commodity chemicals, and pharmaceutical industries. ${ }^{1-3}$ Positional isomerization of double bonds offers a highly attractive route to internal olefins, given the wide availability of terminal olefins and the perfect atom economy of double bond transposition.4-8 However, preparing specific isomers with high stereo- and regioselectivity remains a major challenge in catalyst design. When the desired olefin is by far the most stable isomer, classical methods that use strong acid or high temperature work well.9,10 Isomerization of allylbenzene derivatives is a prime example, with only two possible products and $E$ - $\beta$-methylstyrene strongly thermodynamically favored. ${ }^{3}$ When many products of double bond positional isomerization are possible and some of these are energetically similar, conversely, a poorly selective distribution of alkenes is typically obtained. Transition metal catalysts with custom-tailored supporting ligands can facilitate selective isomerization, exemplified by systems capable of a single stereoselective double bond transposition.11-20

The current paradigm for controlling selectivity is that for each different product, a new metal/ligand combination is needed (Figure 1A). An alternative approach uses a single metal/ligand combination in conjunction with external additives to control the selectivity (Figure 1B). ${ }^{21-25}$ Noncovalent modification has been particularly impactful in the field of alkene hydroformylation, with additives (including alkali metal cations.) $)^{26-31}$ interacting with the catalyst to tune the aldehyde regioselectivity between terminal or secondary positions. ${ }^{32}$ Finding a single catalyst that can access two states that are different enough to have dramatic differences in regioselectivity remains a challenge in hydroformylation. ${ }^{32,33}$ The challenge seems even more daunting for olefin isomerization, where two catalysts states must discriminate between two sterically similar disubstituted internal olefins. We are not aware of any examples of olefin isomerization catalysts that exhibit additive-responsive selectivity.

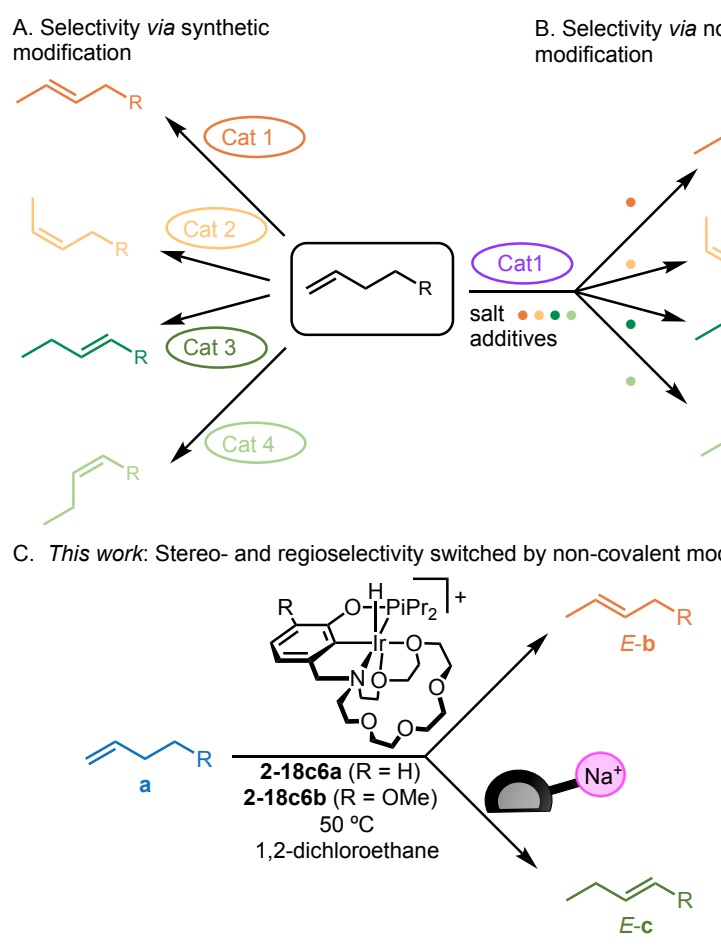

Figure 1. Product selectivity can be tuned via the traditional approach involving preparation of several new synthetically modified catalysts (A) or via an emerging approach based on non-covalent modifications of a single catalyst system (B).

Herein, we introduce new pincer-crown ether iridium hydride catalysts featuring hemilabile aza-18-crown-6 ether receptors that enable olefin isomerization with cation-programmable regioselectivity. In its native state, the pincer-crown ether catalyst isomerizes a range of 1-butenes to the 2-butene regioisomer with high $E$ stereoselectivity (Figure $1 C$ ). In the presence of $\mathrm{Na}^{+}$salts, however, the same catalyst produces 3butenes, exhibiting high degrees of regioselectivity control between two internal double bond positions. Experimental and computational studies provide insight into catalyst design 
principles and thermodynamic landscapes required to access high selectivity in 1-butene isomerizations.

\section{RESULTS}

Synthesis of New Catalysts Featuring Aza-18-crown-6 Ether. Previous studies focused on aza-15-crown-5-etherbased pincer complexes, which performed a single positional isomerization of allylbenzene with rate acceleration by $\mathrm{Li}^{+}$salts (but without any change in selectivity). ${ }^{34-36}$ We hypothesized that iridium complexes containing an aza-18-crown-6 ether would show higher activity, based on binding affinity studies showing very strong and selective binding of $\mathrm{Na}^{+}, 35,37$ enabling the transposition of double bonds over multiple positions.

The aza-18-crown-6-ether-based chloride complex $\kappa^{4}$ $\left({ }^{18 c 6} \mathrm{NCOP}^{\mathrm{iPr}}\right) \operatorname{Ir}(\mathrm{H})(\mathrm{Cl})$ (1-18c6a) was previously reported. ${ }^{38}$ Chloride ligands block olefin binding, however, so a new halidefree complex was sought. In an attempted halide abstraction, 118c6a was treated with $\mathrm{NaBArF}_{4}$ (Figure 2, $\operatorname{Ar}^{\mathrm{F}}=3,5-$ bis(trifluoromethyl)phenyl), but a X-ray diffraction study of the resultant crystals revealed a $\mathrm{Na}^{+}$adduct, $\left[\kappa^{4-}\right.$ $(18 c 6 \mathrm{NCOPiPr}) \operatorname{Ir}(\mathrm{H})(\mathrm{Cl}) @ \mathrm{Na}]\left[\mathrm{BAr}_{4} \mathrm{~F}_{4}\right]$ (1-18c6a@Na, Figure 2), with $\mathrm{Na}^{+}$intercalated by the crown ether and the $\mathrm{Cl}^{-}$bridging to the Ir center. Similar species were proposed as intermediates in on/off rate-switchable isomerization by the 15-crown-5-based catalyst, ${ }^{36}$ although these were not structurally characterized.

Removal of chloride was eventually accomplished by stirring 1-18c6a@Na in 1:1 $\mathrm{CH}_{2} \mathrm{Cl}_{2}: \mathrm{H}_{2} \mathrm{O}$ (Figure 2). The $\mathrm{Na}^{+}$and $\mathrm{Cl}^{-}$ions migrated to the aqueous phase, while the organic phase contained the aqua complex $\left[\mathrm{K}^{5}\right.$ (18c6 NCOPiPr $\left.) \operatorname{Ir}(\mathrm{H})\left(\mathrm{OH}_{2}\right)\right]\left[\mathrm{BAr}_{4}{ }_{4}\right]$ (3-18c6a), which was isolated in $94 \%$ yield. Diagnostic ${ }^{1} \mathrm{H}$ NMR signatures of 3-18c6a include a downfield doublet at $-32.5 \mathrm{ppm}$ for the hydride and a broad singlet at $5.56 \mathrm{ppm}$ that integrates to 2 protons for the bound water. Heating solid 3-18c6a at $145{ }^{\circ} \mathrm{C}$ under vacuum overnight yielded the desired complex $\left[\mathrm{K}^{5}\right.$

$\left.\left({ }^{18 c 6} \mathrm{NCOP}^{\mathrm{iPr}}\right) \operatorname{Ir}(\mathrm{H})\right]\left[\mathrm{BAr}^{\mathrm{F}} 4\right]$ in 98\% yield (2-18c6a, Figure 2).
In the course of this study, we found that adding a methoxy group to the phenyl backbone blocks $\mathrm{C}-\mathrm{H}$ bond activation pathways that lead to catalyst deactivation. ${ }^{39,40}$ Structural comparisons of catalysts with and without "blocking" methoxy groups were therefore sought (Figure 2). The known hydrido chloride complex with the backbone methoxy group, $\kappa^{4-}$ (MeO$\left.{ }^{18 c 6}{ }^{N C O P}{ }^{i P r}\right) \operatorname{Ir}(\mathrm{H})(\mathrm{Cl})(\mathbf{1 - 1 8 c 6 b}),{ }^{38}$ was converted to aqua

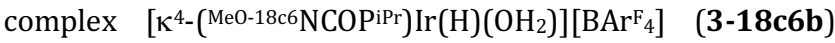
and then the desired catalyst $\left[\kappa^{5}-(\mathrm{MeO}-18 \mathrm{c} 6 \mathrm{NCOPiPr}) \operatorname{Ir}(\mathrm{H})\right]\left[\mathrm{BAr}^{\mathrm{F}} 4\right]$ according to Figure 2.

Both 2-18c6a and 2-18c6b exhibit dynamic behavior in NMR studies. Single broad resonances are observed in ${ }^{31} \mathrm{P}\left\{{ }^{1} \mathrm{H}\right\}$ NMR spectra, and ${ }^{1} \mathrm{H}$ NMR spectra exhibit broadening in many resonances of the crown ether ring. Dynamic behavior was seen as low as $-70 \stackrel{\circ}{\circ}$, suggesting crown ether oxygen hemilability with facile exchange between bound and free oxygen atoms.

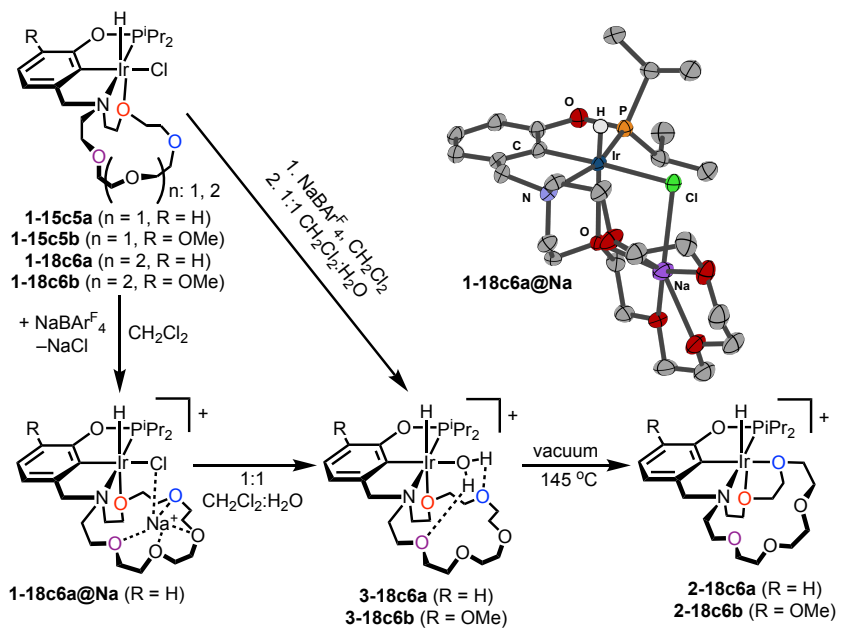

Figure 2. Synthesis of 18-crown-6-based Ir pincer complexes and molecular structure of 1-18c6a@Na from X-ray diffraction
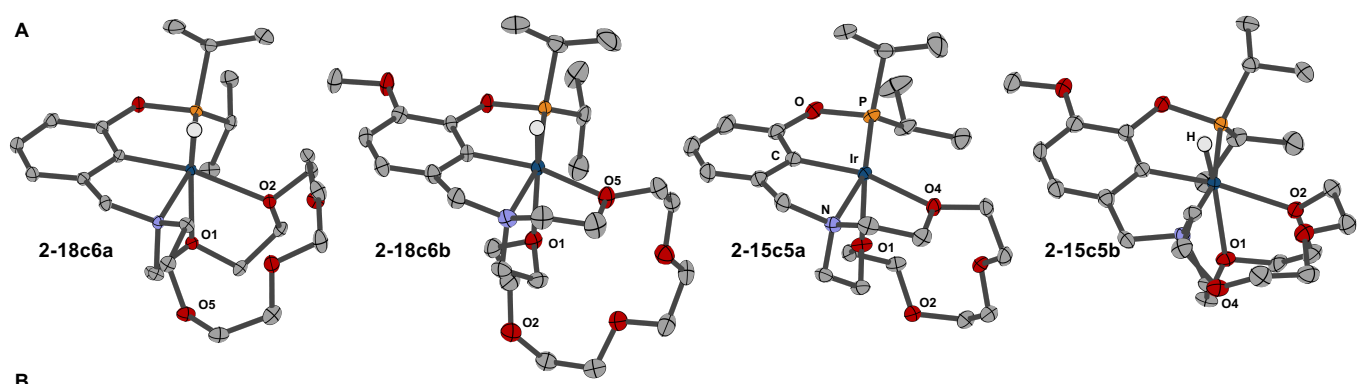

B
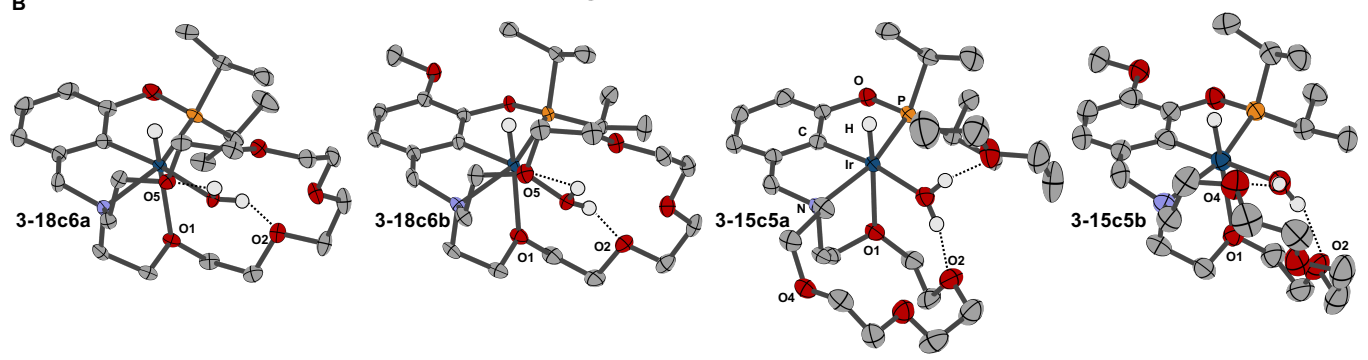

Figure 3. Molecular structures of (A) 2-18c6a/b, alongside renderings of previously published 2-15c5a/b,39,41 and (B) 3$\mathbf{1 8 c 6 a / b}$ and 3-15c5a/b from X-ray diffraction. Thermal ellipsoids at the $50 \%$ probability level. See SI for details. 
study $\left(\mathrm{BArF}_{4}\right.$ anion omitted for clarity, ellipsoids at $50 \%$ probability); the hydride was located in the difference map.

Comparative X-ray diffraction (XRD) studies provided further insight into linkage isomers. The solid-state structure of 2-18c6a features two crown ether oxygen atoms donating to the Ir center (Figure $3 \mathrm{~A}$ ), the oxygen closest to the amine (01) and its nearest neighbor (02). Complex 2-18c6b, however, adopts a different linkage isomer in the solid state, with the two oxygen atoms proximal to the amine (01 and 05) donating to Ir. Distinct linkage isomers were also observed in the previously reported structure of $\mathbf{2 - 1 5} \mathbf{c}^{5} \mathbf{a}^{39,41}$ and a newly acquired structure of $\mathbf{2 - 1 5 c 5 b}$. Computational studies are consistent with the linkage isomers energetically similar (within $3 \mathrm{kcal} / \mathrm{mol}$ ), slightly favoring the isomer with amineadjacent ethers bound to iridium (Figure S54).

Structural comparisons of the aqua complexes are also instructive. As shown in Figure 3B, the large macrocyclecontaining complexes 3-18c6a and 3-18c6b feature one crown ether oxygen (01) binding to the Ir center in the primary coordination sphere, while the bound water engages in hydrogen bonding with two other crown ether oxygen atoms (02 and 05). The hydrogen bonding network in the secondary coordination sphere draws the crown ether macrocycle around the metal center. The flexibility of the larger 18-crown-6 macrocycle enables the ring to fully encapsulate the water ligand, a motif also seen in large metallo-crown complexes with water ligands. ${ }^{42}$ The 15 -crown-5 macrocycle only interacts with the water ligand from one side.

An important conclusion of the synthetic and structural studies is that the size of the macrocycle and the presence of a methoxy group in the pincer backbone induce only subtle changes in catalyst structure and hemilability dynamics. Thus, we anticipated that differences in catalytic activity would be dominated by changes in cation-macrocycle binding affinity.

Influence of Macrocycle Size on Cation-Controlled Olefin Isomerization. To assess the performance of the new 18-crown-6-based catalysts, isomerization of 4-phenyl-1butene (4a) to 4-phenyl-2-butene (4b) was monitored at room temperature by NMR spectroscopy. For simplicity, terminal olefins are labeled $\mathbf{a}$, the isomer with the double bond in the adjacent internal position is labeled $\mathbf{b}$, and the next internal position is labeled $\mathbf{c}$. In the absence of cation, $1 \mathrm{~mol} \% \mathbf{2 - 1 8 c 6 b}$ catalyzed the isomerization of $\mathbf{4 a}$ to $\mathbf{4 b}$ with exceptional 23:1 $E: Z$ stereoselectivity $\left(t_{1 / 2}=190 \mathrm{~h}, \mathrm{TOF}=0.44 \mathrm{~h}^{-1}\right)$. The addition of $\mathrm{NaBArF}_{4}$ salts led to a 4,500-fold rate enhancement $\left(t_{1 / 2}=\right.$ $0.042 \mathrm{~h}, \mathrm{TOF}=1800 \mathrm{~h}^{-1}$ ). The stereoselectivity of $\mathbf{2 - 1 8 c 6 b}$ also changes in the presence of $\mathrm{NaBArF}_{4}$ : even at early times, $E-\mathbf{4 b}$ is only moderately favored $(E: Z=5: 1)$, while $\mathbf{2 - 1 8 c 6 b}$ without salt additives produced $E-\mathbf{4 b}$ with $E: Z$ ratios of 23:1 throughout the reaction (Figure 4B/C). Aqua complex $\mathbf{3 - 1 8 c 6 b}$ is drastically inhibited relative to $\mathbf{2 - 1 8 c 6 b}$ in the absence of salts $\left(t_{1 / 2}=2200 \mathrm{~h}\right.$, TOF $\left.=0.031 \mathrm{~h}^{-1}\right)$. Yet, surprisingly, $\mathbf{3 - 1 8 c 6 b}$ is only slightly slower than the water-free catalyst $\mathbf{2 - 1 8 c 6 b}$ in the presence of $\mathrm{NaBArF}_{4}\left(t_{1 / 2}=0.14 \mathrm{~h}, \mathrm{TOF}=510 \mathrm{~h}^{-1}\right.$, Figure S20).

The new 18-crown-6-based catalyst is superior to the previously reported 15-crown-5-based catalyst in several facets: 2-18c6b isomerizes $\mathbf{4 a}$ up to 10 times faster; the commercially available salt $\mathrm{NaBArF}_{4}$ can be used; and enhanced water tolerance is evident in the salt-promoted reactivity of 3 18c6b.
In considering cation-responsive catalysis to produce different internal olefins, the ability of $\mathrm{Na}^{+}$to alter the activity and stereoselectivity of $\mathbf{2 - 1 8 c 6 b}$ was promising. The reaction profile suggested that salt-free conditions might produce a single stereoselective isomerization, with salt-promoted conditions giving multiple isomerizations.

A.

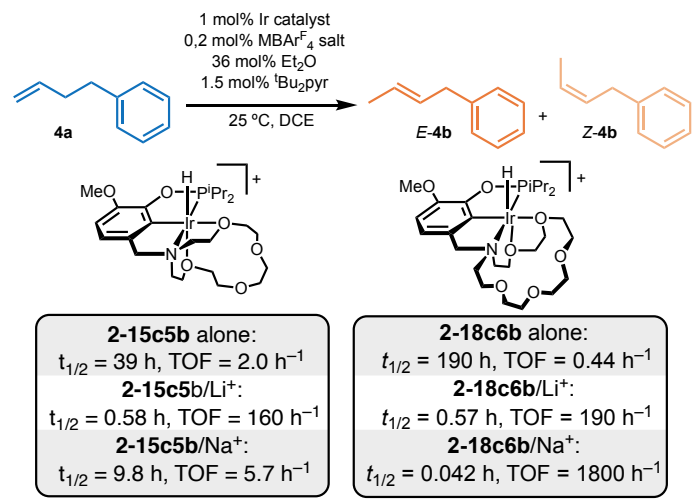

B.

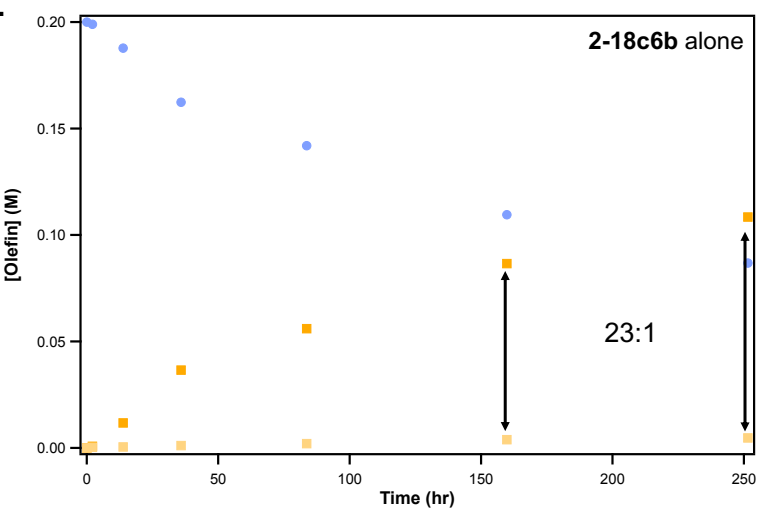

C.

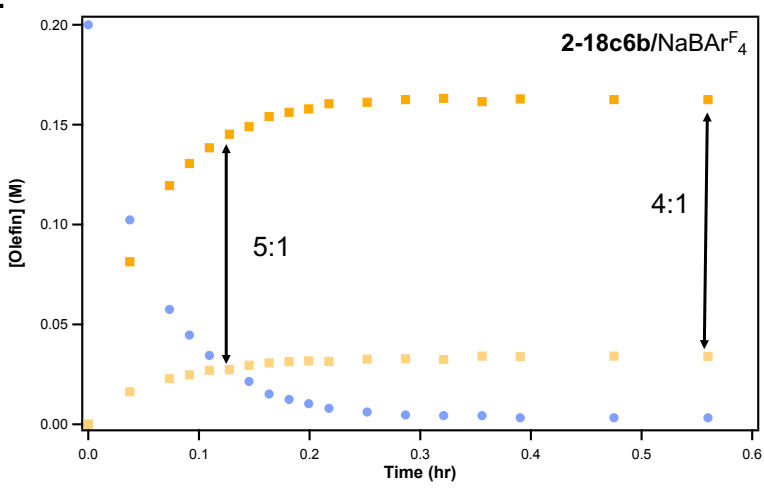

Figure 4. Isomerization of 4-phenyl-1-butene to $E$-4b (dark orange) to $Z-\mathbf{4 b}$ (light orange) by iridium pincer-crown ether catalysts with and without $\mathrm{NaBAr}_{4}$ at $25{ }^{\circ} \mathrm{C}$. The catalytic results are summarized (A), and time course data from NMR monitoring of 2-18c6b alone (B) and in the presence of $\mathrm{NaBAr}_{4}(\mathrm{C})$ reveal distinct catalyst stereoselectivity.

Cation-Switchable Regioselectivity in the Isomerization of 4-Phenyl-1-Butene Derivatives. To probe the ability of $\mathbf{2 - 1 8 c 6 b}$ to produce different internal olefins with different additives, a variety of 4-aryl-1-butenes were treated with 1 mol\% 2-18c6b at $50{ }^{\circ} \mathrm{C}$, with or without $\mathrm{NaBArF}_{4}$. Table 1 shows that $\mathrm{Na}^{+}$controls the regioselectivity and stereoselectivity of the isomerization product. Regioisomer $\mathbf{b}$ is formed in 84 to $95 \%$ yield and 7:1 to $15: 1 E: Z$ selectivity in the 
absence of salts; changing conditions to include $\mathrm{NaBArF}_{4}$ results in formation of regioisomer $\mathbf{c}$ in 79 to $96 \%$ yield and 36:1 to $>90: 1 E: Z$ selectivity (excepting substrate 12).

Table 1. Cation-responsive isomerization of butenyl arenes to either internal isomer.

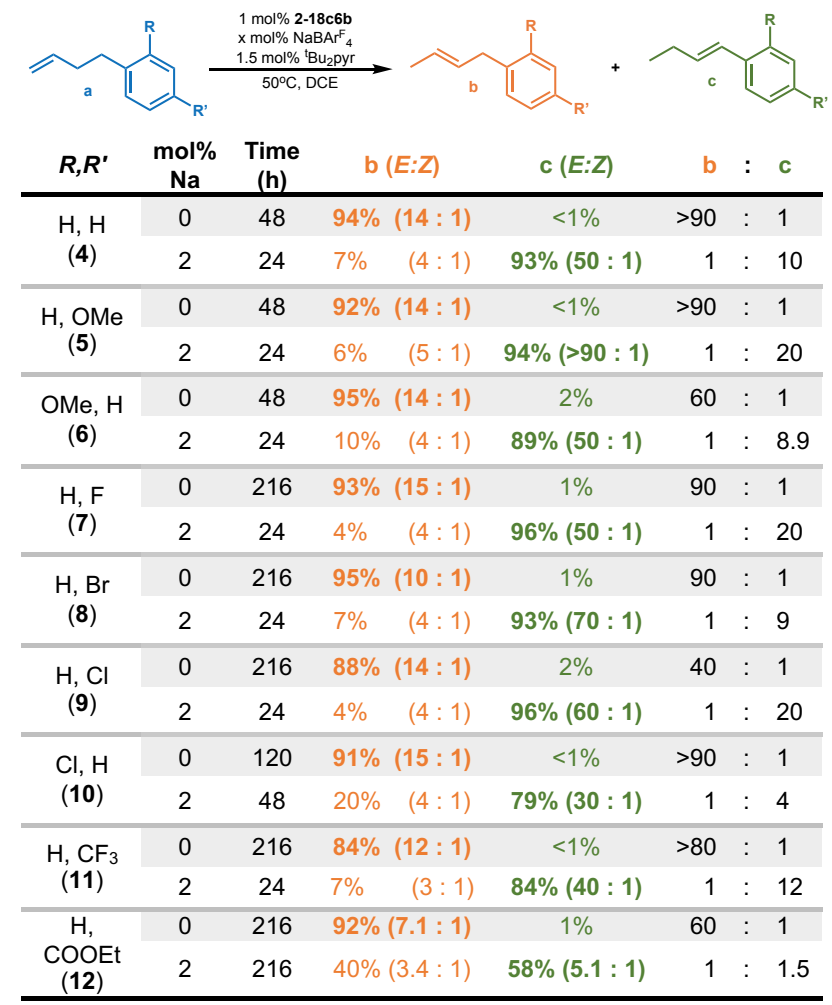

While in principle one could imagine simply running the salt-promoted reaction for short times to obtain the same distribution of $\mathbf{b}$ isomer (and for long times to obtain the $\mathbf{c}$ isomer), this is not possible in practice. The $\mathbf{2 - 1 8 c 6 b} / \mathrm{Na}^{+}$ system produces $\mathbf{b}$ isomers with poor stereoselectivity (see Figure 4C above). The distinct stereoselectivity of the two catalyst states leads to the ability to produce either of two olefin products with high regioselectivity and high stereoselectivity - simply by addition of a $\mathrm{Na}^{+}$salt.

Electron-donating functional groups show faster conversion, in line with prior evidence that substrate binding is the rate limiting step for catalysis. ${ }^{36}$ The ester-functionalized arene 12a reacted slower than other electron deficient substrates even in the presence of $\mathrm{Na}^{+}$. Evidence for inhibition by ester coordination to the catalyst was obtained in the reaction of a 1:1 mixture of ethyl acetate and 4a. After 120 hours at $50 \stackrel{\circ}{\circ}$, only $6 \%$ of $E-4 \mathbf{c}$ isomer was observed, with the dominant product being $\mathbf{4 b}(93 \%)$.

A broader range of 1-butene derivatives was examined next, with the results summarized in Table 2. The aliphatic substrate 4-methyl-1-pentene (13a) could be transposed to either internal regioisomer by cation-responsive catalyst 2 18c6b. Without salts, singly isomerized product 13b was obtained in $94 \%$ yield $(13: 1 \mathrm{E:Z})$; in the presence of $\mathrm{NaBAr}_{4}{ }_{4}$, the doubly isomerized product 13c was obtained in $75 \%$ yield (along with some disubstituted terminal alkene 13d). ${ }^{10}$ Both allyl and vinyl silyl ethers were accessible from the triisopropylsilyl (TIPS)-ether-protected olefin (14a) using 218c6b with the appropriate salt (Table 2). In this case, the $Z$ isomer of 14c was the major product in the presence of $\mathrm{NaBAr}_{4}{ }_{6,43}$ The representative boronic ester 15a underwent isomerization with $\mathbf{2 - 1 8} \mathbf{c} 6$ to give $76 \%$ yield of $\mathbf{1 5 b}(16: 1 \mathrm{E:Z})$. In the presence of $\mathrm{Na}^{+}, \mathbf{1 5 c}$ is formed in $64 \%$ yield with excellent stereoselectivity (16:1 E:Z, Table 2). Olefins with terminal acetal, trimethylsilyl, or acetoxy groups converted to distributions favoring the $\mathbf{b}$ isomer, both with and without salts (Table S1). Although regioselectiviy could not be controlled, the salt-free conditions nonetheless gave high $E$ selectivity for the $\mathbf{b}$ isomer.

Table 2. Cation-responsive isomerization of 1-butenes to either 2- or 3-butenes. ${ }^{a}$

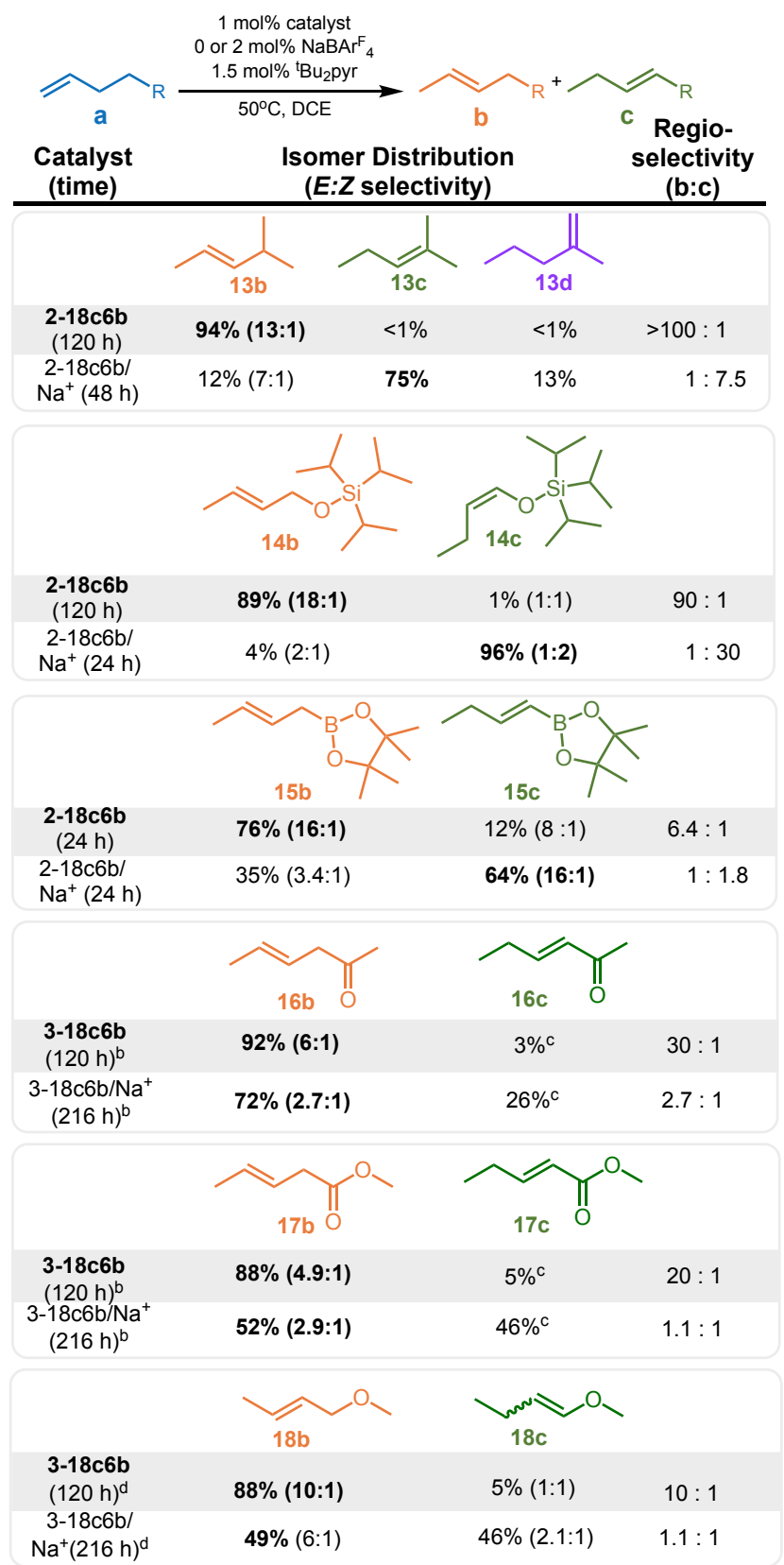

${ }^{a}$ yield of internal isomers; remaining mass balance is starting terminal olefin. ${ }^{b} 5 \mathrm{~mol} \% \mathrm{NaBAr}^{\mathrm{F}}{ }_{4}{ }^{c}$ no $Z$ isomer detected. ${ }^{d} 2.5 \mathrm{~mol} \%$ catalyst. 
Initial examination of 1-butenes with Lewis basic groups revealed sluggish reactivity using catalyst $\mathbf{2 - 1 8 c 6 b}$, even in the presence of $\mathrm{NaBArF}_{4}$ (Figure S45-S47). Hypothesizing that a competing ligand could compete with the Lewis basic groups on the substrate and facilitate product release, we turned to the aqua complex 3-18c6b. Whereas $<5 \%$ c isomer was observed with 2-18c6b/ $\mathrm{Na}^{+}$, switchable regioselectivity was observed with aqua catalyst $\mathbf{3 - 1 8 c 6 b} / \mathrm{Na}^{+}$. Isomerization of 5-hexen-2one (16a) gave $92 \%$ yield of $\mathbf{1 6 b}$ without $\mathrm{NaBAr}_{4}$ and $26 \%$ (16c) with $\mathrm{NaBArF}_{4}$, isomerization of methyl pentenoate (17a) gave $88 \%$ yield of $\mathbf{1 7 b}$ without $\mathrm{NaBAr}_{4}$ and $46 \%$ (17c) with $\mathrm{NaBArF}_{4}$, 4-methoxy-1-butene (18a) gave $88 \%$ of $\mathbf{1 8 b}$; upon the addition of $\mathrm{NaBAr}_{4}, 46 \%$ yield of $18 \mathrm{c}$ was observed.

Table 3. Isomerization of substrates without kinetic and thermodynamic discrimination.

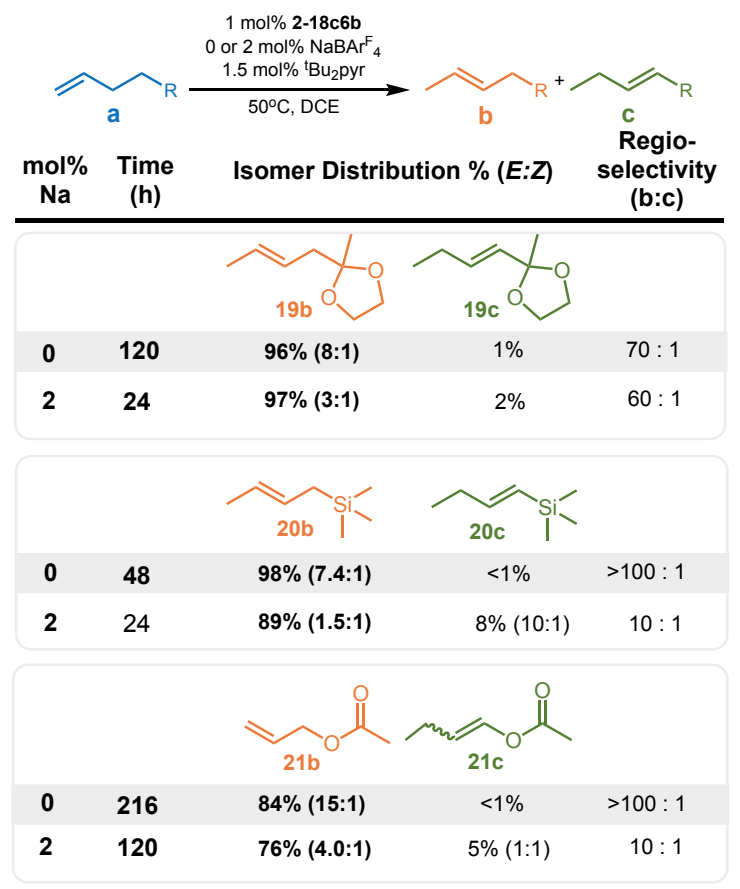

Computational Studies of Relative Energetics of Olefin Isomers. DFT computations were carried out to examine the relative stability of regioisomers of the 1-butene derivatives examined in the catalytic studies. Two methods were compared, each with DCE solvent modeled as a polarizable continuum (further details are provided in the SI). MP244$47 /$ aug-cc-pVDZ48, which has been used to predict isomer distributions of long-chain functionalized olefins, ${ }^{49}$ was compared with B3LYP/6-311++G(d,p); B3LYP/6-311++G(d,p) was found to more accurately reflect experimental values. ${ }^{50,51}$

Figure 5 summarizes the computational results. The 1butene derivatives can be organized into two categories based on their computed thermodynamic distributions of regioisomers. Seven substrates had a distribution where the c regioisomer was the lowest energy species, while three substrates showed a thermodynamic preference for the b regioisomer (Figure 5).

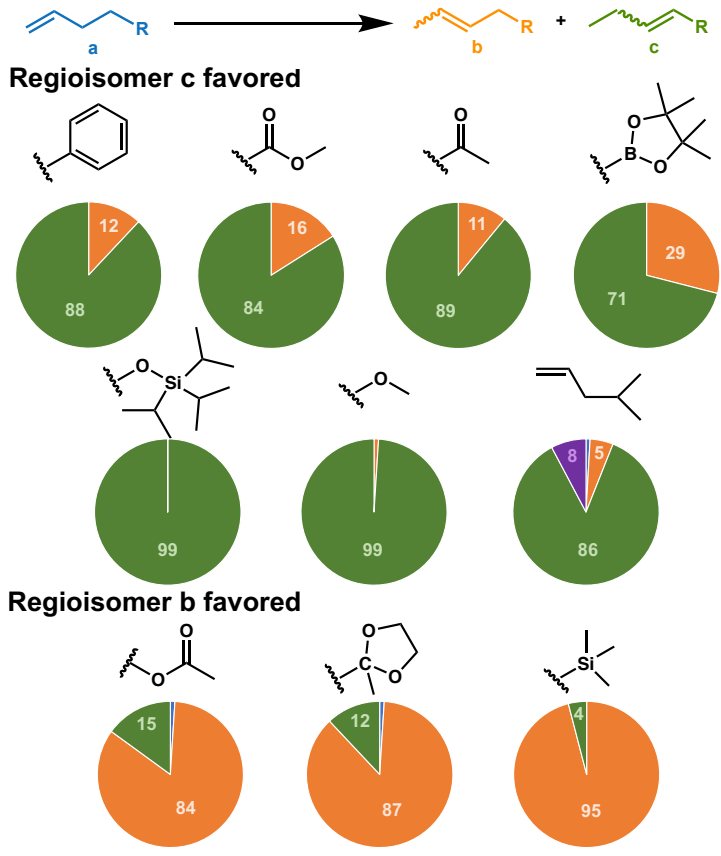

Figure 5. Thermodynamic distributions of 1-butenes from DFT (B3LYP/ 6-311G++(d,p) at $50{ }^{\circ} \mathrm{C}$, and 1,2-dichloroethane continuum solvent model). Over-isomerization to the disubstituted terminal olefin (purple) is thermodynamically accessible in 4-methyl-1-butene.

\section{DISCUSSION}

Proposed mechanism of olefin isomerization and influence of crown ether size. The new complex 2-18c6 is not only a rare catalyst capable of a single positional isomerization with exceptional $E$ stereoselectivity, but also a unique example of a single catalyst that be modified through non-covalent interactions to produce either of two internal isomers. Scheme 1 proposes a mechanism that accounts for the distinct cationcontrolled product distributions. Given the important role of steric interactions in directing selectivity in isomerization, 11,52 we propose that the 2 -selective isomerization stems from a catalyst state featuring a tetradentate $\left(\kappa^{4}\right)$ binding mode with one crown ether oxygen bound during turnover, while the 3selective isomerization takes place from a catalyst state with a tridentate $\left(\kappa^{3}\right)$ binding mode. Spectroscopic monitoring is consistent with a change in resting state, with sharp signals for $\mathbf{2 - 1 8 c 6 b}$ present in salt-free conditions and only very broad resonances detectable in the presence of $\mathrm{NaBAr}_{4}{ }_{4}$. 
Scheme 1. Proposed mechanism of cation-responsive isomerization by iridium pincer-crown ether catalysts.

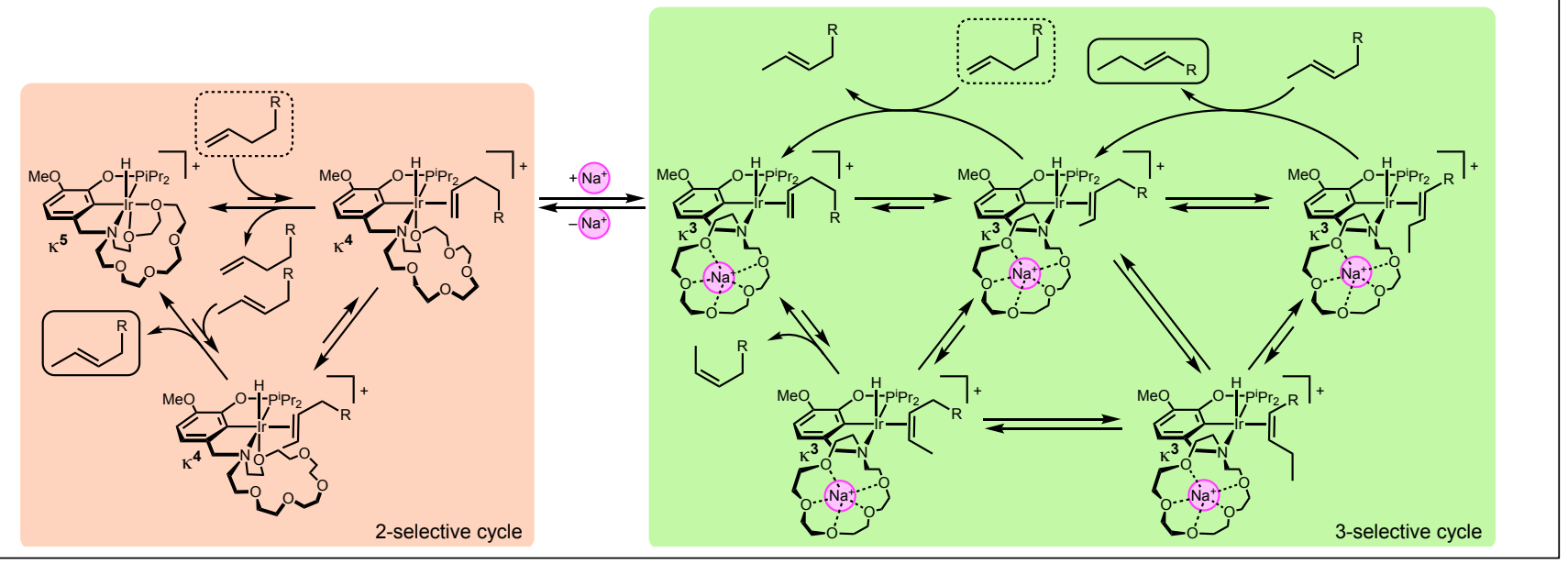

The cation-responsive reactivity of the 18-crown-6-based catalysts was predicted by earlier binding affinity studies of model complexes. ${ }^{36,41}$ Previous binding affinity studies of model nickel and iridium complexes revealed that 15-crown-5based pincer-crown ether complexes bind $\mathrm{Li}^{+}$stronger than $\mathrm{Na}^{+}$, aligning with the high $\mathrm{Li}^{+}$specificity in rate-tunable allylbenzene isomerization with $\mathbf{2 - 1 5} \mathbf{c 5}$ catalysts. ${ }^{36}$ Binding affinity studies of 18-crown-6-based model complexes revealed a similar affinity for $\mathrm{Li}^{+}\left(K_{\mathrm{a}}=34 \mathrm{M}^{-1}\right)$ compared to 15crown-5-based complexes $\left(K_{\mathrm{a}}=76 \mathrm{M}^{-1}\right)$. This led to the successful prediction of similar rates of olefin isomerization for $\mathbf{2 - 1 5} \mathbf{c 6 b}\left(\right.$ TOF $\left.=160 \mathrm{~h}^{-1}\right)$ or $\mathbf{2 - 1 8 c 6 b}\left(\right.$ TOF $\left.=190 \mathrm{~h}^{-1}\right)$ in the presence of $\mathrm{LiBAr}_{4}$. We also successfully predicted that 2 $18 \mathrm{c} 6$ would have much higher $\mathrm{Na}^{+}-$promoted activity than $\mathbf{2 -}$ 15c5, based on the huge difference in binding affinity in model complexes with aza-15-crown-5 $\left(K_{\mathrm{a}}\left(\mathrm{Na}^{+}\right)=19 \mathrm{M}^{-1}\right)$ and aza-18crown-6 $\left(\mathrm{K}_{\mathrm{a}}\left(\mathrm{Na}^{+}\right)=15,000 \mathrm{M}^{-1}\right)$ groups. Indeed, the new catalyst 2-18c6b $\left(\right.$ TOF $\left.=1800 \mathrm{~h}^{-1}\right)$ isomerizes olefins ca. 200 times faster than $\mathbf{2 - 1 5} \mathbf{c 5 b}$ (TOF $\left.=5.7 \mathrm{~h}^{-1}\right)$ in the presence of $\mathrm{NaBAr}_{4}$. The distinct reactivity of the salt adduct interplays with thermodynamics of the olefinic products to explain the observed switchable behavior.

Understanding Regioselectivity Control. Switchable regioselectivity is accessed across a wide range of butenes. In the absence of salts, the catalyst 2-18c6b (or 3-18c6b) facilitates a single isomerization of the double bond to the first internal position, producing the $\mathbf{b}$ isomer in high yield and with high regioselectivity and high stereoselectivity (favoring the $E$ isomer). The ratio of $\mathbf{b}: \mathbf{c}$ regioisomers without salts often exceeded 40:1. In the presence of $\mathrm{NaBAr}_{4}$, the doubly isomerized product is formed instead, also in high yield and favoring the $E$ isomer (b:c ratio typically beyond 1:8).

The crux of the switchable reactivity is the thermodynamic landscape of olefin isomerization. Comparing the computed regioisomer distributions with the experimental outcomes under different conditions, it is clear that the catalytic reactions in the presence of $\mathrm{NaBAr}_{4}$ generate the most thermodynamically favored isomer (the "thermodynamic product"). Conversely, the regio- and stereoselectivity of reactions catalyzed by $\mathbf{2 - 1 8 c 6 b}$ in the absence of salts are consistent with a high degree of kinetic control: the thermodynamic product is not obtained, and instead a specific and less stable isomer is produced. Thus, the switchable

selectivity stems from a cation-induced change between kinetic control and thermodynamic control.

A

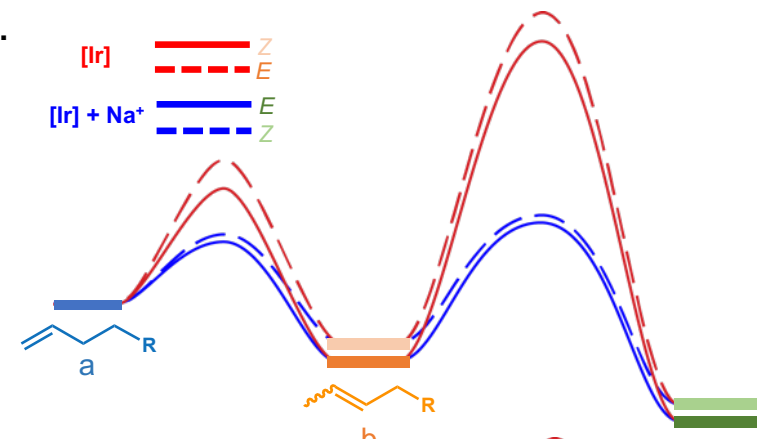

B.

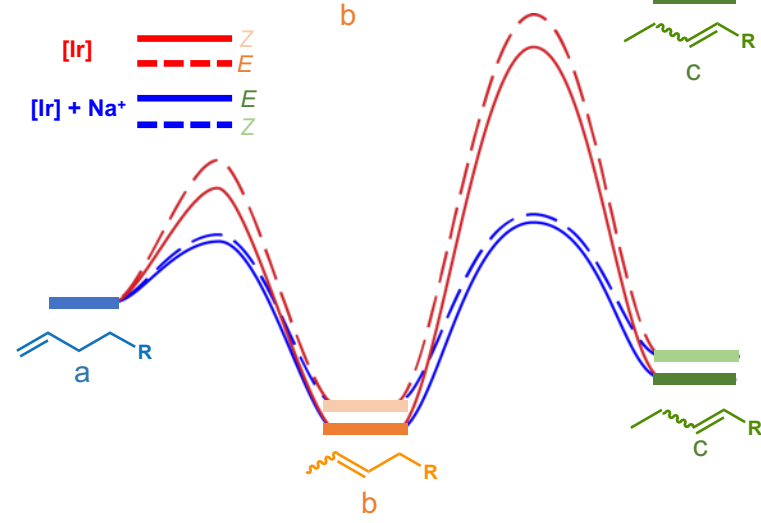

Figure 6. Simplified reaction coordinate diagrams depicting substrates where cation-controlled selectivity is possible (A) and where thermodynamic limitations prevent access to the $\mathrm{c}$ isomer (B).

The general features of the reaction coordinate diagrams depicted in Figure 6A are shared by each substrate for which switchable regioselectivity was observed. A "stair-step" stability pattern is apparent, with the starting terminal olefin a being the least stable, isomer $\mathbf{b}$ being intermediate, and isomer c being the thermodynamic product (due to $\pi$-conjugation or hyperconjugation). In the absence of a salt, the kinetic barrier to convert $\mathbf{a}$ to $\mathbf{b}$ is surmountable, but further isomerization to regioisomer $\mathbf{c}$ is not observed (even with prolonged reaction times). The kinetic product $\mathbf{b}$ is thus obtained, and $\mathbf{2 - 1 8 c 6 b}$ 
alone produces high yields of this isomer with exquisite regioselectivity (and stereoselectivity, see below). If instead the reaction is performed with $\mathrm{NaBAr}^{\mathrm{F}}$, the barriers for all isomerizations are reduced dramatically, and the reaction proceeds under thermodynamic control to the most stable regioisomer. Even with $\mathrm{NaBArF}_{4}$, butenes containing Lewis basic groups faced kinetic barriers when using 2-18c6b. Better control over regioselectivity was obtained with the aqua catalyst 3-18c6b.

The non-responsive reactivity of butenes with silyl, acetyl, and ketal substituents can be explained by a change in thermodynamic landscape: DFT calculations reveal that isomer $\mathbf{c}$ is not the most stable species in these cases, with $\mathbf{b}$ being favored instead. As shown in Figure 6B, the same regioisomer will be produced regardless of whether the reaction is under kinetic or thermodynamic control.

Rationalizing Unique Stereoselectivity in Each Catalytic State. The pincer-crown ether catalyst $\mathbf{2 - 1 8 c 6 b}$ is one of a select few catalysts capable of facilitating a single positional isomerization with exceptional stereoselectivity for the $E$-isomer. ${ }^{5,52-56}$ It is unique in selectively accessing either of two internal isomers in response to an external stimulus.

The high stereoselectivity of pincer-crown ether catalysts in the absence of salts ( $E: Z$ ratios often exceeding 15:1 even at $50{ }^{\circ} \mathrm{C}$ ) was not previously recognized because prior studies focused on isomerization of allylbenzene. ${ }^{36}$ The $E$ isomer of the product $\beta$-methylstyrene is highly favored thermodynamically ( $E: Z$ ca. $20: 1$ at $25^{\circ} \mathrm{C}$ ), obscuring any kinetic selectivity of the catalyst. 57 The butene-containing substrates, in contrast, have only a moderate thermodynamic preference for the $E$ isomer (ca. $E: Z$ 4:1).5,58

The high stereoselectivity of $\mathbf{2 - 1 8 c 6 b}$ in the absence of salts is proposed to originate from steric congestion of the crown ether (Scheme 1). Computational studies have shown that the Ir-O bond trans to phenyl are easiest to dissociate, which can open up a binding site for alkene to bind. ${ }^{41}$ Without salts, we hypothesize that one crown ether oxygen remains bound to the Ir center during catalysis, providing additional steric pressure that can influence selectivity by favoring the transition state that forms the $E$ isomer and disfavoring internal olefin binding.

The stereoselectivity of $\mathbf{2 - 1 8 c 6 b}$ changes upon the addition of $\mathrm{NaBAr}_{4}$, leading to thermodynamic distributions of $E$ and $Z$ isomers. For example, isomerization of $\mathbf{4 a}$ with $\mathbf{2 -}$ 18c6b/NaBArF 4 produces $4 \mathbf{b}$ with selectivity close to the expected thermodynamic distribution $(E: Z=4: 1)$. As shown in Scheme 1, we propose that $\mathrm{Na}^{+}$binding leads to cleavage of both Ir-O bonds and release of steric pressure near the active site. This is consistent with prior studies of model complexes showing negligible cation binding by pincer-crown ether complexes with tetradentate $\left(\kappa^{4}\right)$ or pentadentate $\left(\kappa^{5}\right)$ binding modes, but strong binding when tridentate $\left(\kappa^{3}\right)$ binding modes with no bound ether oxygens are adopted. ${ }^{37}$ The mechanistic model of Scheme 1 helps explain why shortening the reaction

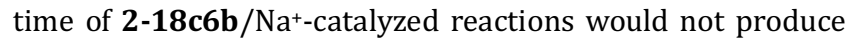
the same outcome as the salt-free system: each catalytic state has a distinct structure and thus distinct stereoselectivity.

Design Principles for Non-Covalent Catalyst Modification. The prevailing paradigm in catalyst design involves synthetic tuning of supporting ligands. In this work, we explore a complementary strategy based on non-covalent modification of the catalyst structure.21-25 There are no prior examples of a single catalyst that can produce either of two internal olefin isomers through the influence of an external additive, to our knowledge. Thus, our mechanistic insight can provide some initial design principles for how cationcontrolled selectivity in isomerization reactions may be achieved.

A catalyst should be able to access two states, each with a unique reactivity. One state must provide high selectivity for a kinetic product; the other state can either selectively form a different kinetic product or form the thermodynamic product. Prior knowledge of the thermodynamic landscape of the isomers under consideration is helpful in this regard: in our case, computational investigations rapidly identified systems where the 2-isomer was the thermodynamic product, such that the two catalyst states would have identical selectivity. An additional requirement is that the two states must not interconvert rapidly. In this case, strong cation-macrocycle interactions maintain the second state.

Steric factors have proven essential in controlling the selectivity in olefin isomerization. Grotjahn and coworkers observe distinct selectivity based on the cyclopentadienyl substitution pattern in $\mathrm{Ru}$ catalysts,7,59 for example, and Jiao, Liu, and coworkers saw large variations in selectivity as a function of steric parameter in pincer-ligated Co catalysts. 60 These observations suggest that the two catalyst states in a responsive system should be sterically distinct. Here we propose that the change in selectivity stems from a structural change in the primary coordination sphere via changes in ether ligand hemilability. When one ether remains bound to the catalyst, the kinetic product is obtained; when no ethers are bound to the catalyst, the thermodynamic product is instead produced. Thus, modifications that alter ligand lability or the primary coordination sphere may be expected to have strong impacts on reaction selectivity in other catalysts as well.

Changing the primary coordination sphere via external additives in order to control selectivity is notably distinct from the prevailing approach to non-covalent catalyst modification. Typically, additives interact with the supporting ligand (or two supporting ligands interact with each other) to change the overall steric profile or the ligand bite angle, without altering the coordination number. This strategy has been highly effective in tuning the linear/branched regioselectivity in alkene hydroformylation,24,33 including examples of cationcrown interactions tuning ligand bite angle.26,27,30 Because the macrocycle in pincer-crown ether is directly bound to the catalyst, cation binding influences the primary coordination sphere, which we propose to be essential for controlling regioselectivity and stereoselectivity between two sterically similar internal olefin isomers.

\section{CONCLUSIONS}

A single cation-responsive pincer-crown ether iridium catalyst can produce either of two internal isomers using appropriate external additives. In the absence of salts, 2-18c6b isomerizes 1-butene derivatives to the corresponding 2-butene with exceptional regio- and stereoselectivity. Under otherwise identical conditions, but in the presence of $\mathrm{NaBAr}_{4}$, the doubly isomerized 3-butenes are produced. Combined experimental and computational studies guided the development of a model that explains the selectivity outcomes. Two distinct catalytic 
state are accessed, one (salt-free) that exhibits high kinetic selectivity for a single $E$-selective isomerization, and another (salt-activated) that exhibits thermodynamic selectivity. Cation-macrocycle interactions are proposed to change the pincer ligand binding mode, resulting in distinct activity and selectivity traits. Selective generation of individual internal olefin isomers from a single catalyst offers promise for the diversification of olefins relevant to the fragrance, and pharmaceutical, and other industries.

\section{Supporting Information}

Experimental details and characterization data (PDF)

Crystallographic data (CIF)

\section{Corresponding Author}

* A.J.M.M. Email: ajmm@email.unc.edu

\section{Acknowledgment}

The experimental work was supported through NSF CAREER award CHE-1553802. The authors thank M. ter Horst for assistance with NMR spectroscopy experiments. The NMR spectroscopy work was supported by the National Science Foundation under Grant No. CHE-1828183 and Grant No. CHE0922858. The mass spectrometry work was supported by the National Science Foundation under Grant No. CHE-1726291.

\section{References}

(1) Larsen, C. R.; Grotjahn, D. B. The Value and Application of Transition Metal Catalyzed Alkene Isomerization in Industry. In Applied Homogeneous Catalysis with Organometallic Compounds; Cornils, B., Herrmann, W. A., Beller, M., Paciello, R., Eds.; Wiley-VCH Verlag: Weinheim, Germany, 2018; pp 1365-1378.

(2) Donohoe, T. J.; O’Riordan, T. J. C.; Rosa, C. P. RutheniumCatalyzed Isomerization of Terminal Olefins: Applications to Synthesis. Angew. Chemie - Int. Ed. 2009, 48, 1014-1017.

(3) Hassam, M.; Taher, A.; Arnott, G. E.; Green, I. R.; van Otterlo, W. A. L. Isomerization of Allylbenzenes. Chem. Rev. 2015, $115,5462-5569$.

(4) Li, H.; Mazet, C. Iridium-Catalyzed Selective Isomerization of Primary Allylic Alcohols. Acc. Chem. Res. 2016, 49, 12321241.

(5) Kocen, A. L.; Klimovica, K.; Brookhart, M.; Daugulis, O. Alkene Isomerization by "Sandwich" Diimine-Palladium Catalysts. Organometallics 2017, 36, 787-790.

(6) Yamasaki, Y.; Kumagai, T.; Kanno, S.; Kakiuchi, F.; Kochi, T. Selective Long-Distance Isomerization of Terminal Alkenes via Nondissociative Chain Walking. J. Org. Chem. 2018, 83, 9322-9333.

(7) Grotjahn, D. B.; Larsen, C. R.; Gustafson, J. L.; Nair, R.; Sharma, A. Extensive Isomerization of Alkenes Using a Bifunctional Catalyst: An Alkene Zipper. J. Am. Chem. Soc. 2007, 129, 9592-9593.

(8) Molloy, J. J.; Morack, T.; Gilmour, R. Positional and Geometrical Isomerisation of Alkenes: The Pinnacle of Atom Economy. Angew. Chemie Int. Ed. 2019, 58, 13654-13664.

(9) Dunning, H. N. Review of Olefin Isomerization. Ind. Eng. Chem. 1953, 45, 551-564.

(10) Sparke, M. B.; Turner, L.; Wenham, A. J. M. The Isomerization of Olefins by Palladium Complexes. J. Catal. 1965, 4, 3323340 .

(11) Chen, C.; Dugan, T. R.; Brennessel, W. W.; Weix, D. J.; Holland, P. L. Z -Selective Alkene Isomerization by High-Spin Cobalt(II) Complexes. J. Am. Chem. Soc. 2014, 136, 945-955.

(12) Lim, H. J.; Smith, C. R.; RajanBabu, T. V. Facile Pd(II)- and $\mathrm{Ni}(\mathrm{II})$-Catalyzed Isomerization of Terminal Alkenes into 2Alkenes. J. Org. Chem. 2009, 74, 4565-4572.

(13) Becica, J.; Glaze, O. D.; Wozniak, D. I.; Dobereiner, G. E. Selective Isomerization of Terminal Alkenes to ( $\mathrm{Z}$ )-2Alkenes Catalyzed by an Air-Stable Molybdenum(0) Complex. Organometallics 2018, 37, 482-490.
Larsen, C. R.; Grotjahn, D. B. Stereoselective Alkene Isomerization over One Position. J. Am. Chem. Soc. 2012, 134, 10357-10360.

(15) Crossley, S. W. M.; Barabé, F.; Shenvi, R. A. Simple, Chemoselective, Catalytic Olefin Isomerization. J. Am. Chem. Soc. 2014, 136, 16788-16791.

(16) Scarso, A.; Colladon, M.; Sgarbossa, P.; Santo, C.; Michelin, R. A.; Strukul, G. Highly Active and Selective Platinum(II)Catalyzed Isomerization of Allylbenzenes: Efficient Access to (E)-Anethole and Other Fragrances via Unusual Agostic Intermediates. Organometallics 2010, 29, 1487-1497.

(17) Kapat, A.; Sperger, T.; Guven, S.; Schoenebeck, F. E-Olefins through Intramolecular Radical Relocation. Science (80-. ). 2019, 396, 391-396.

(18) Schmidt, A.; Nödling, A. R.; Hilt, G. An Alternative Mechanism for the Cobalt-Catalyzed Isomerization of Terminal Alkenes to ( Z )-2-Alkenes. Angew. Chemie Int. Ed. 2015, 54, 801-804. McGowan, K. P.; Abboud, K. A.; Veige, A. S. Trianionic NCN3Pincer Complexes of Chromium in Four Oxidation States (CrII, CrIII, CrIV, CrV): Determination of the Active Catalyst in Selective 1-Alkene to 2-Alkene Isomerization. Organometallics 2011, 30, 4949-4957.

(20) Meng, Q.; Schirmer, T. E.; Katou, K.; König, B. Controllable Isomerization of Alkenes by Dual Visible-Light-Cobalt Catalysis. Angew. Chemie - Int. Ed. 2019, 131, 5779-5784.

(21) Vlatković, M.; Collins, B. S. L.; Feringa, B. L. Dynamic Responsive Systems for Catalytic Function. Chem. - A Eur. J. 2016, 22, 17080-17111.

(22) McConnell, A. J.; Wood, C. S.; Neelakandan, P. P.; Nitschke, J. R. Stimuli-Responsive Metal-Ligand Assemblies. Chem. Rev. 2015, 115, 7729-7793.

(23) Blanco, V.; Leigh, D. A.; Marcos, V. Artificial Switchable Catalysts. Chem. Soc. Rev. 2015, 44, 5341-5370.

(24) Raynal, M.; Ballester, P.; Vidal-Ferran, A.; Van Leeuwen, P. W. N. M. Supramolecular Catalysis. Part 1: Non-Covalent Interactions as a Tool for Building and Modifying Homogeneous Catalysts. Chem. Soc. Rev. 2014, 43, 16601733.

(25) Vaquero, M.; Rovira, L.; Vidal-Ferran, A. Supramolecularly Fine-Regulated Enantioselective Catalysts. Chem. Commun. 2016, 52, 11038-11051.

(26) Owens, S. B.; Gray, G. M. Study of the Effects of Alkali Metal Salts on Styrene Hydroformylation Reactions Catalyzed by Rhodium(I) Complexes of Bis(Phosphite) Ligands. Organometallics 2008, 27, 4282-4287.

(27) Martin, J. R.; Cagle, E. C.; Lucius, A. L.; Gray, G. M. Correlating the Activity of Rhodium(I)-Phosphite-Lariat Ether Styrene Hydroformylation Catalysts with Alkali Metal Cation Binding through NMR Spectroscopic Titration Methods. Organometallics 2016, 35, 2609-2620.

(28) Mon, I.; Jose, D. A.; Vidal-Ferran, A. Bis(Phosphite) Ligands with Distal Regulation: Application in Rhodium-Mediated Asymmetric Hydroformylations. Chem. - A Eur. J. 2013, 19, 2720-2725.

(29) Vidal-Ferran, A.; Mon, I.; Bauzá, A.; Frontera, A.; Rovira, L. Supramolecularly Regulated Ligands for Asymmetric Hydroformylations and Hydrogenations. Chem. - A Eur. J. 2015, 21, 11417-11426.

(30) Rovira, L.; Vaquero, M.; Vidal-Ferran, A. Asymmetric Hydroformylation of Heterocyclic Olefins Mediated by Supramolecularly Regulated Rhodium-Bisphosphite Complexes. J. Org. Chem. 2015, 80, 10397-10403.

(31) Di Stefano, S.; Capocasa, G.; Mandolini, L. Supramolecular Catalysts Featuring Crown Ethers as Recognition Units. European J. Org. Chem. 2020, 2020, 3340-3350.

(32) Nurttila, S. S.; Linnebank, P. R.; Krachko, T.; Reek, J. N. H. Supramolecular Approaches to Control Activity and Selectivity in Hydroformylation Catalysis. ACS Catal. 2018, 8 , 3469-3488.

(33) Bai, S. T.; Sinha, V.; Kluwer, A. M.; Linnebank, P. R.; Abiri, Z.; Dydio, P.; Lutz, M.; De Bruin, B.; Reek, J. N. H. Effector Responsive Hydroformylation Catalysis. Chem. Sci. 2019, 10, 7389-7398.

(34) Smith, J. B.; Miller, A. J. M. Connecting Neutral and Cationic Pathways in Nickel-Catalyzed Insertion of Benzaldehyde into 
a C-H Bond of Acetonitrile. Organometallics 2015, 34, 46694677.

(35) Smith, J. B.; Camp, A. M.; Farquhar, A. H.; Kerr, S. H.; Chen, C.H.; Miller, A. J. M. Organometallic Elaboration as a Strategy for Tuning the Supramolecular Characteristics of Aza-Crown Ethers. Organometallics 2019, 38, 4392-4398.

(36) Kita, M. R.; Miller, A. J. M. An Ion-Responsive Pincer-Crown Ether Catalyst System for Rapid and Switchable Olefin Isomerization. Angew. Chemie Int. Ed. 2017, 56, 5498-5502.

(37) Smith, J. B.; Kerr, S. H.; White, P. S.; Miller, A. J. M. Thermodynamic Studies of Cation-Macrocycle Interactions in Nickel Pincer-Crown Ether Complexes Enable Switchable Ligation. Organometallics 2017, 36, 3094-3103.

(38) Yoo, C.; Dodge, H. M.; Farquhar, A. H.; Gardner, K. E.; Miller, A. J. M. Poly(Ether) Dissection by Pincer Iridium-Mediated Ether Decarbonylation.

(39) Dodge, H. M.; Kita, M. R.; Chen, C.-H.; Miller, A. J. M. Controlling Pincer Ligand Hemilability to Avoid Off-Cycle Intermediates in Cation-Tunable Olefin Isomerization.

(40) Gregor, L. C.; Grajeda, J.; White, P. S.; Vetter, A. J.; Miller, A. J. M. Salt-Promoted Catalytic Methanol Carbonylation Using Iridium Pincer-Crown Ether Complexes. Catal. Sci. Technol. 2018, 8, 3133-3143.

(41) Kita, M. R.; Miller, A. J. M. Cation-Modulated Reactivity of Iridium Hydride Pincer-Crown Ether Complexes. J. Am. Chem. Soc. 2014, 136, 14519-14529.

(42) Gray, G. M. Metallacrown Ethers: Unique Organometallic Ligands. Comments Inorg. Chem. 1995, 17, 95-114.

(43) Ohmura, T.; Yamamoto, Y.; Miyaura, N. Stereoselective Synthesis of Silyl Enol Ethers via the Iridium-Catalyzed Isomerization of Allyl Silyl Ethers. Organometallics 1999, 18, 413-416.

(44) Frisch, M. J.; Head-Gordon, M.; Pople, J. A. A Direct MP2 Gradient Method. Chem. Phys. Lett. 1990, 166, 275-280.

(45) Frisch, M. J.; Head-Gordon, M.; Pople, J. A. Semi-Direct Algorithms for the MP2 Energy and Gradient. Chem. Phys. Lett. 1990, 166, 281-289.

(46) Head-Gordon, M.; Pople, J. A.; Frisch, M. J. MP2 Energy Evaluation by Direct Methods. Chem. Phys. Lett. 1988, 153, 503-506.

(47) Head-Gordon, M.; Head-Gordon, T. Analytic MP2 Frequencies without Fifth-Order Storage. Theory and Application to Bifurcated Hydrogen Bonds in the Water Hexamer. Chem. Phys. Lett. 1994, 220, 122-128.

(48) Woon, D. E.; Dunning, T. H. Gaussian Basis Sets for Use in Correlated Molecular Calculations. V. Core-Valence Basis Sets for Boron through Neon. J. Chem. Phys. 1995, 103, 4572-4585.

(49) Kohls, E.; Stein, M. The Thermochemistry of Long Chain Olefin Isomers during Hydroformylation. New J. Chem. 2017, 41, 7347-7355.

(50) Krishnan, R.; Binkley, J. S.; Seeger, R.; Pople, J. A. No Title. J. Chem. Phys. 1980, 72, 650.

(51) Mclean, A.D; Chandler, G. S. J. Contracted Gaussian Basis Sets for Molecular Calculations. I. Second Row Atoms, Z=11-18. J. Chem. Phys. 1985, 72, 5639.

(52) Larsen, C. R.; Erdogan, G.; Grotjahn, D. B. General Catalyst Control of the Monoisomerization of 1-Alkenes to Trans -2Alkenes. J. Am. Chem. Soc. 2014, 136, 1226-1229.

(53) Kobayashi, T.; Yorimitsu, H.; Oshima, K. Cobalt-Catalyzed Isomerization of 1-Alkenes to (E)-2-Alkenes with Dimethylphenylsilylmethylmagnesium Chloride and Its Application to the Stereoselective Synthesis of (E)Alkenylsilane. Chem. - An Asian J. 2009, 4, 1078-1083.

(54) Wang, Y.; Qin, C.; Jia, X.; Leng, X.; Huang, Z. An Agostic Iridium Pincer Complex as a Highly Efficient and Selective Catalyst for Monoisomerization of 1-Alkenes to Trans-2Alkenes. Angew. Chemie - Int. Ed. 2017, 56, 1614-1618.

(55) Liu, X.; Zhang, W.; Wang, Y.; Zhang, Z.-X.; Jiao, L.; Liu, Q. Cobalt-Catalyzed Regioselective Olefin Isomerization Under Kinetic Control. J. Am. Chem. Soc. 2018, 140, 6873-6882.

(56) Yu, X.; Zhao, H.; Li, P.; Koh, M. J. Iron-Catalyzed Tunable and Site-Selective Olefin Transposition. J. Am. Chem. Soc. 2020, jacs.0c08631.

(57) Taskinen, E.; Lindholm, N.; Nummelin, K.; Taskinen, E.
Relative Thermodynamic Stabilities of the Isomeric Propenylbenzenes. J. Phys. Org. Chem. 1994, 7, 256-258.

(58) Paulson, E. R.; Delgado, E.; Cooksy, A. L.; Grotjahn, D. B. Catalyst versus Substrate Control of Forming (E)-2-Alkenes from 1-Alkenes Using Bifunctional Ruthenium Catalysts. Org. Process Res. Dev. 2018, 22, 1672-1682.

(59) Paulson, E. R.; Moore, C. E.; Rheingold, A. L.; Pullman, D. P.; Sindewald, R. W.; Cooksy, A. L.; Grotjahn, D. B. Dynamic PiBonding of Imidazolyl Substituent in a Formally 16-Electron Cp Ru(2-P, N)+ Catalyst Allows Dramatic Rate Increases in (E)-Selective Monoisomerization of Alkenes. ACS Catal. 2019, 9, 7217-7231.

(60) Liu, X.; Zhang, W.; Wang, Y.; Zhang, Z. X.; Jiao, L.; Liu, Q. Cobalt-Catalyzed Regioselective Olefin Isomerization under Kinetic Control. J. Am. Chem. Soc. 2018, 140, 6873-6882. 
TOC Graphic

select between two products with $\mathrm{Na}^{+}$salt

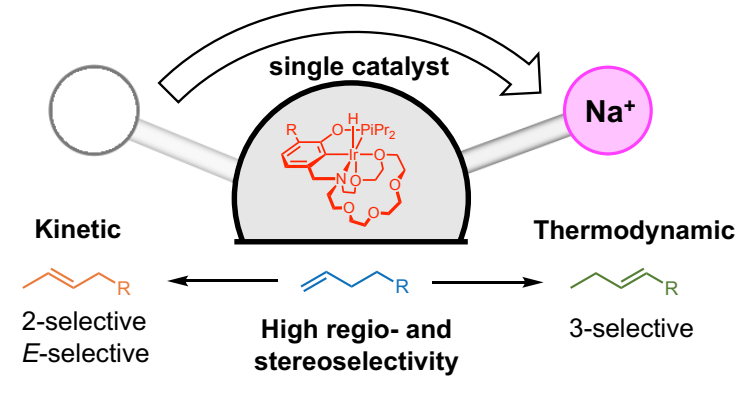

